\title{
Sterols enriched fractions obtained from Agaricus bisporus fruiting bodies and by-products by compressed fluid technologies (PLE and SFE)
}

\author{
Alicia Gil-Ramírez*1, Laila Aldars-García ${ }^{1}$, Marimuthu Palanisamy ${ }^{1}$, Rodica M. \\ Jiverdeanu' ${ }^{1}$, Alejandro Ruiz-Rodríguez ${ }^{1}$, Francisco R. Marín', Guillermo \\ Reglero $^{1,2}$, Cristina Soler-Rivas ${ }^{1}$ \\ ${ }^{1}$ Department of Production and Characterization of Novel Foods, CIAL-Research \\ Institute in Food Science (UAM+CSIC), C/Nicolas Cabrera 9, Campus de \\ Cantoblanco, Universidad Autónoma de Madrid, 28049 Madrid, Spain. \\ ${ }^{2}$ Imdea-Food Institute. CEI UAM+CSIC. C/ Faraday 7, 28049 Madrid, Spain.
}

*Corresponding author. Tel:+34-910017971 ; Fax: +34-910017905 E-mail address: alicia.gil@uam.es

Running title: Sterols extraction by PLE and SFE from A. bisporus

KEYWORDS: ergosterol, cholesterol, accelerated solvent extraction (ASE), Supercritical $\mathrm{CO}_{2}$ extraction, button mushroom 


\section{ABSTRACT}

Ergosterol, ergosta7,22 dienol, ergosta 5,7 dienol, fungisterol, ergosta-4,7,2-trien-3ona and ergosta-4,6,8(14),22-tetraen-3-ona were the fungal sterols detected in Agaricus bisporus mushrooms after optimization of an sterol extraction method. Their concentration ranged from 3.1- $11.2 \mathrm{mg} / \mathrm{g} \mathrm{dw}$ depending on the strain, casing soil, flush number, developmental stage and sporophore tissue analyzed. Two methods were optimized to obtain sterols enriched extracts from A. bisporus fruiting bodies using pressurized fluid (PLE) and supercritical fluid extractions (SFE). PLE using ethanol as solvent at $10.7 \mathrm{MPa}\left(50^{\circ} \mathrm{C}\right.$ and $\left.100^{\circ} \mathrm{C}\right)$ after 5 cycles of 5 min extraction (mixing in the extraction cell the sample with sand in a ratio 1:4) yielded extracts with respect. 5 and $2.9 \%$ sterols. Using $\mathrm{SFE}-\mathrm{CO}_{2}$ at $40^{\circ} \mathrm{C}$ and 9 to $30 \mathrm{MPa}$ fractions containing $60 \%$ of sterols were obtained. Both technologies could be also utilized to extract sterols from mushroom by-products (the lower part of the stipe) as a method for their valorization. 


\section{Introduction}

Cardiovascular diseases (CVD) are one of the leading causes of death in industrialized countries. Although, up to $80 \%$ of the cases could be prevented by changing style life, advertises of public agencies do not have the impact they should. Nowadays, only the consumption of functional foods with hypocholesterolemic properties seems to be better accepted by the CVD risk population than other changes. The functional foods, available at the markets, bearing the claim `able to reduce cholesterol levels in serum' contain mainly plant phytosterol (Ling \& Jones, 1995; Turnham, 1999), or cereal $\beta$-glucans. The mechanism of action of the hypocholesterolemic $\beta$-glucans is not completely elucidated (Cheickna \& Hui, 2012) while apparently the phytosterols are able to impair cholesterol absorption by displacing it from the dietary mixed micelles (DMM) formed during digestion (Jesch \& Carr, 2006). Phytosterols share structural similarity with cholesterol balancing their competitive equilibrium for the DMMs toward their inclusion enhancing cholesterol precipitation and excretion (Valenzuela \& Ronco, 2004). Other mechanisms of action mentioned for some phytosterols included the inhibition of the ACAT (acylCoA:cholesterol acyltransferase) a key enzyme involved in the cholesterol absorption by intestinal enterocytes and modification at the mRNA and protein expression levels of NPC1L1 and ABC transporters (proteins involved in cholesterol transport mechanisms) (Davis et al., 2004).

Edible mushrooms also contain sterols with structural similarities to phytosterols and cholesterol. Thus, these fungal molecules might also act as phytosterols displacing

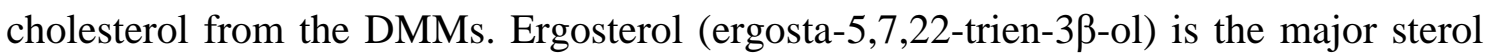
of their hyphae membranes (approx. $80 \%$ of the sterols w/w) followed by other 
derivatives such as ergosta-5,8,22-trien-3-ol, ergosta-7,22-dien-3-ol, ergosta-5,7-dien-3ol and ergosta-7-en-3-ol (fungisterol) Their presence and concentration is specie dependent influenced by many other environmental factors (Yokokawa \& Mitsuhashi, 1981; Teichmann, Dutta, Staffas, \& Jagerstad, 2007; Mattila, Lampi, Ronkainen, Toivo, \& Piironen, 2007; Kalač, 2009; Senatore, Dini, Marino \& Schettino, 1988).

Pressurized liquid extraction (PLE) and supercritical fluids extraction (SFE) are environmentally-friendly advance technologies utilized for the extraction or removal of specific fractions of interest for the food industry (Mendiola, Herrero, Cifuentes \& Ibañez, 2007). These technologies are nowadays encouraged because of ecological concerns and because they share the advantage of using non toxic and/or GRAS solvents such as water, ethanol or $\mathrm{CO}_{2}$. The latter can easily evaporate after the extraction and depressurization leaving no solvent trace in the extract. Compressed fluid technologies such as SFE with $\mathrm{CO}_{2}$ were utilized to obtain triterpenoids (with similar rings than ergosterol molecules) from reishi mushrooms (Ganoderma lucidum), carboxylic and fatty acids from Agaricus spp., antioxidant and antimicrobial compounds from the fruiting bodies of shiitake mushrooms (Lentinula edodes) and antitumoral fractions from Cordyceps sinensis mycelia (Hsu, Lin \& Chen, 2001; Ibrahim Abdullah, Young \& Games 1994; Kitzberger, Smania, Pedrosa \& Ferreira, 2007; Kitzberger, Lomonaco, Michielin, Danielski, Correia \& Ferreira, 2009; Wang, Won, Yu \& Su, 2005). SFE and supercritical fluid chromatography were also utilized in flour and moldy bread for ergosterol detection as indicator of fungal contamination (Young \& Games, 1993). PLE was utilized for the selective isolation of polysaccharides from several fungal species (Fan, Li, Chu, Zhang \& Yan, 2012; Palanisamy et al., 2012; Di, Chan, 
Leung \& Huie, 2003; Lo, Tsao, Wang \& Chang, 2007) and certain fatty acids from Cordyceps spp. (Yang, Feng, Zhao \& Li, 2009).

In this work, ergosterol and derivatives were measured in several Agaricus bisporus varieties during different cultivation parameters, developmental stages, sporophore tissues etc. The sterols were extracted by both SFE and PLE technologies in order to compare them and define the optimal method and extraction parameters to obtain sterols-enriched fractions. Extractions were carried out using the complete fruiting body or the lower part of the stipe usually discarded as a by-product during harvesting to investigate the possible revalorization of this by-product as starting material to generate ergosterol-enriched fractions for novel functional ingredients with hypocholesterolemic properties.

\section{Materials and Methods}

\subsection{Biological material}

Commercialized spawns of Agaricus bisporus L. (Imbach) were cultivated under controlled conditions (temperature, H.R. and $\mathrm{CO}_{2}$ ) at CTICH (Centro Tecnológico de Investigación del Champiñón de La Rioja, Autol, Spain). Fruiting bodies obtained from different flushes $\left(1^{\text {st }}\right.$ to $3^{\text {rd }}$ flush) or cultivated under different conditions (the same substrate but with 2 different casing layers) were harvested at developmental stage 2-3 according to Hamond et al. (1979) (except when the influence of the developmental stage was studied). In some cases, the different sporophore tissues, including the lower part of the stipe, were separately collected and treated as below described for fruiting bodies. 
The fruiting bodies were sliced, lyophilized and ground using a Grindomix GM200 Retsch mill, (VERDER Group, The Netherland) as described by Ramírez-Anguiano et al. (2007). Mushroom powders were stored at $-20^{\circ} \mathrm{C}$ and in darkness until further use.

\subsection{Standards and reagents}

Solvents as hexane (95\%), cyclohexane (HPLC grade), chloroform (HPLC grade) and methanol (HLPC grade) were obtained from LAB-SCAN (Gliwice, Polland) and absolute ethanol and sea sand from Panreac (Barcelona, Spain). Potassium hydroxide, ascorbic acid and BHT (2,6-Di-tert-butyl-p-cresol) as well as hexadecane, and (22E)ergosta-5,7,22-trien-3 $\beta$ were purchased from Sigma-Aldrich Química (Madrid, Spain). Ergosterol (96\% purity) was obtained from Alfa Aesar GmbH \& Co (Karlsruhe, Germany). $\mathrm{CO}_{2}$ was supplied by Air-Liquid España,S.A. (Madrid, Spain). All other reagents and solvents were used of analytical grade.

\section{3. $\quad$ Pressurized Liquid Extraction (PLE)}

Agaricus bisporus mushroom powder (1g) was mixed with washed sea sand (4g) and submitted to pressurized solvent extraction using an Accelerated Solvent Extractor (ASE) (Dionex Corporation, ASE 350, USA). The sea sand was selected as an inert material to hold the sample inside the extraction cell and to improve efficiency avoiding formation of preferential flow paths. Extraction procedure (per cycle) was carried out at $10.68 \mathrm{MPa}(1500 \mathrm{psi})$ as follows: firstly, the sample was loaded into $11 \mathrm{ml}$ extraction cell, then, the cell was filled with ethanol, heated-up and static extraction was carried out during the selected minutes with all system valves closed. When a cycle was 
finished, the cell was rinsed, the solvent was purged out of the cell with $\mathrm{N}_{2}$ gas and the cell remained depressurized. Then, fresh solvent was again added to the extraction cell to carry out another extraction cycle until the programmed number of cycles was finished. The fractions collected after the selected cycles were pooled together in a vial as a single extract.

Several parameters such as static extraction time, number of cycles, ratio mushroom powder/sand and temperature were changed in order to optimize the extraction method to obtain fractions enriched in fungal sterols.

After collection, the extracts were immediately placed on a rotary vacuum extractor (Ika RV10 - VWR, PA, United States), concentrated until dryness (at $30^{\circ} \mathrm{C}$ ) and stored at $-20^{\circ} \mathrm{C}$ until further analysis. Extracted dry matter content was measured to calculate the extraction yields. All the experiments were carried out in duplicate.

\subsection{Supercritical fluid extractions (SFE)}

Supercritical fluid extractions with $\mathrm{CO}_{2}$ (pilot-plant scale) were carried out in a plant (TharTechnology, Pittsburgh, PA, USA, model SF2000) comprising a 2L cylinder extraction cell and two different separators each of 0.5 L capacity (S1 and S2) with independent control of temperature and pressure. The extraction vessel has a ratio of 5.5 height/diameter. A detailed explanation of the experimental device can be found elsewhere (García-Risco, Vicente, Reglero \& Fornari, 2011). Extraction cell was filled with $80 \mathrm{~g}$ of mushroom powder and $900 \mathrm{~g}$ of washed sea sand. In order to optimize the extraction method to obtain fractions enriched in fungal sterols, parameters such as extraction pressure (30, 18 and $9 \mathrm{MPa}$ ) and the use of a co-solvent (ethanol, $10 \% \mathrm{w} / \mathrm{w}$ ) 
were tested. Extraction temperature as well as temperature of separators 1 and 2 was set to $40^{\circ} \mathrm{C}$ for all the experimental assays. Pressure of separator 1 and separator 2 using ethanol as co-solvent was maintained at 6 and $0.1 \mathrm{MPa}$ respectively, however during $\mathrm{CO}_{2}$ extraction both separators were kept at $6 \mathrm{MPa}$ pressure. The $\mathrm{CO}_{2}$ flow was set at $3.4 \mathrm{~kg} / \mathrm{h}$ and the total extraction time was $3 \mathrm{~h}$. Extracted compounds were precipitated in separator 1 in all assays. In the extractions with the co-solvent, separators were emptied every half hour. At the end of extraction process, the fractions were dragged with ethanol and immediately submitted to concentration until dryness on a rotary vacuum evaporator. Dried extract was stored at $-20^{\circ} \mathrm{C}$ until further analysis. Extracted dry matter content was measured to calculate the extraction yields. All the experiments were carried out in duplicate.

\section{5. $\quad$ Fungal sterols extraction method}

Fungal sterols from mushrooms were extracted following the procedure described by Mattila et al. (2002) with modifications. Briefly, the mushroom samples or extracts $(0.2$ g) and $0.3 \mathrm{~g}$ of ascorbic acid were mixed with $15 \mathrm{ml}$ of $11.5 \% \mathrm{KOH}$ in methanol:water $(55: 45 \mathrm{v} / \mathrm{v})$ and vigorously stirred for $15 \mathrm{~min}$ at $80^{\circ} \mathrm{C}$. Afterwards, the mixture was cooled down and $10 \mathrm{ml}$ of $0.01 \%(\mathrm{w} / \mathrm{v})$ BHT in hexane were added. The mixture was shacked during $2 \mathrm{~min}$ and left at room temperature $(5 \mathrm{~min})$ until complete separation of the phases. Organic fraction was collected and $5 \mathrm{ml}$ BHT solution were added to the aqueous fraction for a second extraction. Both organic phases were pooled together in a round bottom flask and evaporated on a rotary vacuum extractor at $30^{\circ} \mathrm{C}$ until dryness. Dry extracts were dissolved in a $\mathrm{ClCH}_{3}: \mathrm{MeOH}(2: 1 \mathrm{v} / \mathrm{v})$ solution including hexadecane as internal standard and submitted to GC-MS-FID analysis. 


\section{6. $\quad G C-M S-F I D$ analysis}

The unsaponificable fraction obtained from the mushroom extracts was injected (2 $\mathrm{mg} / \mathrm{ml}$ ) into an Agilent 19091S-433 capillary column (30m x $0.25 \mathrm{~mm}$ ID and $0.25 \square \mathrm{m}$ phase thickness). The column was connected to a 7890A System gas chromatograph (Agilent Technologies, USA) equipped with an electronic pressure control, G4513A auto injector, a 5975C triple-Axis mass spectrometer detector, and GC-MS Solution software. The injector was set at $260^{\circ} \mathrm{C}$, the detector at $350^{\circ} \mathrm{C}$ and the oven temperature program followed the method described by Teichman et al. (2007) with modifications: $60^{\circ} \mathrm{C}$ for $1 \mathrm{~min}$, at a rate of $40^{\circ} \mathrm{C} / \mathrm{min}$, to a final temperature of $310^{\circ} \mathrm{C}$, held for $30 \mathrm{~min}$. Helium was used as carrier gas at a flow of $29.4 \mathrm{ml} / \mathrm{min}$ and inlet pressure of $0.19 \mathrm{MPa}$.

Ergosterol was used as standard to develop and validate the GC method, using hexadecane $(10 \% \mathrm{v} / \mathrm{v})$ as internal standard. Linearity, LOD, LOQ, precision and reproducibility were determined following the ICH guidelines (1996) and IUPAC technical report of 2002 (Thompson, Ellison \& Wood, 2002).

According to the GC-MS database, the identified the peaks were in concordance with previous studies (Teichmann, Dutta, Staffas, \& Jagerstad, 2007; Jasinghe \& Perera,

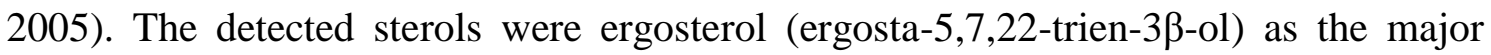
sterol $(\mathrm{RT}=13.3 \mathrm{~min})$ being $83 \%$ of the total sterols content followed by ergosta $7,22-$ dienol $(\mathrm{RT}=13.6 \mathrm{~min})$, ergosta-5,7-dienol $(\mathrm{RT}=14.0 \mathrm{~min})$ and ergosta-7-enol (fungisterol) $(\mathrm{RT}=14.3 \mathrm{~min})$. Two other derivatives ergosta-4,7,2-trien-3-ona $(\mathrm{RT}=$ $14.9 \mathrm{~min})$ and ergosta-4,6,8(14),22-tetraen-3-ona ( $\mathrm{RT}=15.7 \mathrm{~min})$ were also detected but in very low concentration. 


\subsection{Statistical data analysis}

Significance differences between variables were determined by the Fisher test $(\alpha=$ 0.05) using Statgraphics Plus (Statistical Graphics Corporation, Manugistics Inc., MD, USA 1997).

\section{Results and discussion}

\subsection{Selection of the starting material for sterols extractions}

A screening within several commercial A. bisporus strains was carried out in order to define the optimal starting material for the sterols extractions. Similarly, the influence of other cultivation parameters (casing soil, flush number, developmental stage and tissue distribution) in their sterols content was also determined. The total fungal sterols content of $A$. bisporus mushrooms using the modified extraction method ranged from 3.1- $11.2 \mathrm{mg} / \mathrm{g} \mathrm{dw}$ thus results were in concordance with previous reports (Teichmann, Dutta, Staffas, \& Jagerstad, 2007; Mattila, Lampi, Ronkainen, Toivo, \& Piironen, 2007)

Firstly, the fungal sterols content was measured in the fruiting bodies harvested from substrates inoculated with different spawn varieties (Table 1). Two of the Agaricus bisporus strains (Fungisem H15 and Mispaj 365) showed significantly higher ergosterol levels than the others although the levels of the minor sterols were similar.

No significant differences in sterols content were found within fruiting bodies (Fungsiem H15) obtained from the first, second or third flush when the mushrooms were cultivated using as casing layer a mixture of $70 \%$ black and $30 \%$ blonde peat. However, when only black peat was utilized, lower sterol levels were observed in 
mushrooms from the third flush. Mushrooms from the third flush are usually of lower quality than the previous flushes because when the third flush arises almost all nutrients from the substrate have been consumed thus, their hyphae grow less, they are weaker and their levels of ergosterol are reduced (as this molecule is considered as a maker for the fungal biomass and nutrition status (Barajas-Aceves, Hassan, Tinoco \& VazquezDuhalt, 2002).

The sterols content was also measured during the development of the fruiting bodies (from the first flush). Results indicated that the largest sterol content occurred during the faster growth phase of the sporophore formation (Table 1). At the initial primordial stage, pin heads readjust their metabolic mechanisms in order to synthesize the fruiting bodies, then, their hyphal extension is not very significant. However immediately after, they start their exponential growth (immature stage), mushrooms almost double their size in a few hours indicating large development of hyphal membranes and therefore large ergosterol biosynthesis. Afterwards, senescence processes begins to open their caps and expose their gills therefore the hyphal as well as ergosterol synthesis stopped.

The sterol distribution within the different sporophore tissues was also evaluated (Table 1). Results indicated that ergosterol levels were higher in the veil and gills than in other cap tissues. Interestingly, the lower part of the stipe usually discarded as byproduct also showed high sterols levels. The distribution of the other minor sterols was similar than for ergosterol except for the levels of ergosta-5,7 dienol that were slightly higher in skin and flesh than in the other tissues.

Thus, Agaricus bisporus (Fungisem H15) fruiting bodies from the first flush and harvested at the stage 2-3 according to Hammond et al. (1979) were selected as starting material to obtain fungal sterols enriched fractions by PLE and SFE. 


\section{2. $\quad$ Sterols enriched fractions by Pressurized Liquid Extraction (PLE)}

Several parameters were tested in order to optimize the ASE conditions to obtain sterols-enriched extracts using ethanol as pressurized liquid (10.7MPa) such as extraction temperature, static extraction time, number of cycles or amount of sample inserted in the extraction cell (ratio mushroom: sand (w/w)).

\subsubsection{Influence of extraction temperature}

Accelerated solvent extractions carried out to obtain polysaccharide enriched fractions from A. bisporus fruiting bodies were largely influenced, beside the type of solvent, by the extraction temperature (Palanisamy et al., 2012). Thus, in order to investigate the influence of the temperature in the sterol extraction yields, ASE extractions were performed maintaining fixed other parameters ( 5 cycles of 5 minutes each one with a ratio 1:4 mushroom:sand $(\mathrm{w} / \mathrm{w}))$ and changing temperature from $25^{\circ}$ up to $200^{\circ} \mathrm{C}$. Results indicated that the extraction yield (\%) increased with the temperature from approx. $5 \%$ at $25^{\circ} \mathrm{C}$ to almost $52 \%$ of the total dry matter at $200^{\circ} \mathrm{C}$ (Table 2). Thus, extractions at $200^{\circ} \mathrm{C}$ were less selective for total sterols since only $1 \%$ of the obtained fractions were sterols while at lower temperatures $\left(25\right.$ and $\left.50^{\circ} \mathrm{C}\right)$ less material was obtained but they accounted for almost 5-6\% of the extracted material.

However, in terms of quantitative amounts of sterols obtained from the mushroom powder, increasing of temperature generated higher sterols recovery rates $(\mathrm{mg} / \mathrm{g}$ sample). In the samples carried out at $25^{\circ} \mathrm{C}$ four folds less sterols were extracted that the amount present in the fruiting body $(7.5 \mathrm{mg} / \mathrm{g})$ and temperatures higher than $100^{\circ} \mathrm{C}$ were necessary to extract most of them. Thus, extraction temperatures of $50^{\circ} \mathrm{C}$ and $100^{\circ} \mathrm{C}$ 
were selected for further testing since fraction obtained at $50^{\circ} \mathrm{C}$ showed the highest sterols concentration $(6 \%)$ and at $100^{\circ} \mathrm{C}$ almost all the extractable sterols present in the mushroom were obtained.

When the influence of the extraction temperature was evaluated within the individual sterols, no specific temperature could be selected to preferentially extract one of the sterol derivatives more than the others. Apparently, temperature similarly influenced the extraction of ergosterol and the other derivatives.

\subsubsection{Influence of extraction time}

Total extraction time can be adjusted by modifying two parameters: by changing the time in which the sample remains in the extraction cell (static time) or the number of extraction cycles. Both conditions were studied.

Thus firstly parameters such as temperature $\left(50\right.$ and $\left.100^{\circ} \mathrm{C}\right)$, ratio mushroom: sand 1:4 (w/w) and 5 cycles were set and extractions were carried out at 1, 5, 10 and 15 minutes per cycle (total extraction times were respectively 5, 25, 50 and $95 \mathrm{~min}$ ). Results indicated that at $50^{\circ} \mathrm{C}$ the extraction yields were higher after $5 \mathrm{~min}$; further increase of the extraction time did not increase the extracted dry matter (Table 3). However, if the extractions were carried out at $100^{\circ} \mathrm{C}$ shorter extraction time was required. The total sterol concentration of the obtained extracts was more influenced by the extraction temperature than by the extraction time.

When results were compared in terms of sterol concentrations extracted per gram of mushroom powder, only extractions carried out at $100^{\circ} \mathrm{C}$ and 1 min per cycle were able to extract all the sterols present in the mushroom (Figure 1a). In the extractions carried 
out during $10-15 \mathrm{~min}$ (per cycle) at $100^{\circ} \mathrm{C}$ and $15 \mathrm{~min}$ at $50^{\circ} \mathrm{C}$, a slightly increase of ergosta5,7-dienol could be noticed suggesting that long extraction times beside sterols degradation they might also induce transformation between them.

Changing of the extraction cycles instead of static extraction time (set at 5 min per cycle) maintaining the same total extraction times (5, 25, 50 and $95 \mathrm{~min})$ was also studied (at 50 and $100^{\circ} \mathrm{C}$ ). Results showed that extraction yields increased with the number of cycles at both temperatures however, differences were only significant between 1 and 5 cycles at $50^{\circ} \mathrm{C}$ and further increase in the number of cycles did not result in significantly higher extraction yield (Table 3). Thus, the extractions carried out during 5 cycles of 5 min yielded the ASE extracts with higher sterol concentrations reaching almost $5 \%$ of the extract at $50^{\circ} \mathrm{C}$. Extractions of 5 cycles were also pointed as the condition to extract more sterols from the mushroom at both 50 and $100^{\circ} \mathrm{C}$ (Figure 1b). As observed with the increasing of the static extraction time, more extraction cycles also induced shifting of some sterols into others (at $100^{\circ} \mathrm{C}$ ). Particularly if the 10 cycles extractions were compared with those of 15 cycles, the total sterol concentrations were in both cases similar but a small reduction in the ergosterol content was noticed in the latter towards a slight increase of the other three identified sterol derivatives.

The sterol yields of the obtained ASE fractions collected after 50 and 95 min (total time) were different depending on the condition changed (static time or number of extraction cycles) (Table 3). Apparently, longer contact time between the sample and the solvent is a more effective extraction process than extracting using more solvent (as occurred if the number of cycles is increased). 


\subsubsection{Influence of ratio mushroom/sand}

The amount of sample placed into the extraction cell was another of the tested parameters to ensure that the cell was not saturated and that the sample is homogeneously distributed forming no aggregates. Several ratios mushroom: sand $(\mathrm{w} / \mathrm{w})$ were tested fixing the total material weight inside the cell $(5 \mathrm{~g})$ and the rest of extraction parameters $\left(5\right.$ extraction cycles of $5 \mathrm{~min}$ at $50^{\circ}$ and $\left.100^{\circ} \mathrm{C}\right)$. As expected, the ASE extraction yield was increasing with the amount of sample utilized at both temperatures (Table 3). However, the sterols content in the extracted samples showed no significantly differences in the ratios 1:9 and 1:4 mushroom: sand (w/w).

When results were expressed as amount of sterols extracted from the amount of mushroom powder loaded in the cell, no significant differences were observed if the total sterol concentrations were compared indicating that the cell was not saturated. However, extractions using a ratio 1:19 (mushroom: sand) contained higher levels of fungisterol, ergosta 5,7-dienol and ergosta-7,22-dienol than using two or four folds higher amount of sample where ergosterol was in these cases between 80 - 95\% of the total sterols (Figure 1c). Differences were observed at the two selected temperatures being more significant at $100^{\circ} \mathrm{C}$. Apparently, if lower amount of sample is utilized for ASE extractions, the extraction times should be again properly adjusted because $25 \mathrm{~min}$ (total extraction time) provoked similar transformation effects between sterols than the one observed at longer extraction times (95 $\mathrm{min}$ ) when the ratio 1:4 (mushroom:sand) was utilized. 


\section{3. $\quad$ Sterols enriched fractions by Supercritical fluid extraction (SFE)}

Agaricus bisporus fruiting bodies were also submitted to supercritical fluids extractions (SFE) with $\mathrm{CO}_{2}$ to evaluate whether they were more effective for fungal sterols extraction than PLE. Several extraction conditions were tested such as pressure $(9,18$ and $30 \mathrm{MPa})$ and use of $10 \%(\mathrm{v} / \mathrm{v})$ ethanol as co-solvent. Previous studies stated that an increase of temperature (from 40 up to $60^{\circ} \mathrm{C}$ ) did not enhance the extraction yield as remarkably as it did when using PLE (Mazzutti, Ferreira, Riehl, Smania, Smania \& Martínez, 2012) therefore; the extraction temperature was set to $40^{\circ} \mathrm{C}$ for the entire set of experiments.

Results indicated that extraction yields were more influenced by the presence of ethanol as co-solvent than by the extraction pressure (Figure 2a). The highest extraction yields were obtained using $\mathrm{CO}_{2}$ with ethanol as co-solvent. This was due to the fact that, regardless of the pressure tested, the mixture widened the extracting polarity range leading to an increase in the amount of extracted compounds. Similar extraction yields were reported in previous studies carried out using other mushroom species such as Lentinula edodes (approx $0.5 \%$ and $2.5 \%$ with $10 \%$ ethanol), Agaricus brasiliensis (also known as Agaricus blazei) $(0.85-0.98 \%$ at $10-30 \mathrm{MPa}$ and up to $4 \%$ with $10 \%$ ethanol as co-solvent) and Ganoderma lucidum (1.3 - 1.6\%) (Hsu, Lin \& Chen, 2001; Kitzberger, Smania, Pedrosa \& Ferreira, 2007; Mazzutti, Ferreira, Riehl, Smania, Smania \& Martínez, 2012). Opposite to what was expected, differences between the extraction yields resulting from different extraction pressures were not significant. This might be explained because at $9 \mathrm{MPa}$ all possible extractable matter was already extracted. These results were also in agreement with those above mentioned reports using other mushroom species. 
However, sterol concentrations were higher in the SFE extracts where only $\mathrm{CO}_{2}$ was used as extraction solvent than in those extracts obtained with $\mathrm{CO}_{2}$ modified with $10 \%$ ethanol (Figure 2b). These differences might be due to the higher extraction yield obtained with ethanol addition. When only $\mathrm{CO}_{2}$ was used, no significant differences in the sterol concentration were found within the extracts obtained at different pressures however, the fraction obtained at $30 \mathrm{MPa}$ with $\mathrm{CO}_{2}$ and $10 \%$ ethanol showed a significantly lower sterol content than the extracts obtained at lower pressures.

The amount of sterols extracted with SFE using $\mathrm{CO}_{2}$ and ethanol as co-solvent represented the $80 \%$ of the total sterols present in A. bisporus fruiting bodies however, only $50 \%$ of the sterols were extracted when only $\mathrm{CO}_{2}$ was used.

When the influence of the extraction conditions were evaluated within the individual sterols content, the use of the ethanol as co-solvent appeared to extract a significantly higher amount of ergosta-7,22-dienol $(6.57 \%$ of the total sterols $)$ than without it (3.61\%) (Figure 3). Particularly in the extractions carried out at $30 \mathrm{MPa}$, the higher levels of this sterol (9.2\% of the total sterols) appeared to correlate with the lower ergosterol level (74\% while on average, in the rest of the extractions was $77.8 \%$ ) indicating that perhaps shifting between sterol structures might also take place with increasing of pressures as observed in PLE extractions. Moreover, the ratio of the minor sterols within the total sterol levels seemed higher in SFE than in PLE obtained extracts. 


\section{4. $\quad$ Sterols enriched fractions from A.bisporus by-products}

The lower part of the stipe of the A. bisporus sporophore is usually cut and discarded during harvesting because it is stained with the attached casing soil and depreciate the quality of the fruiting bodies during storage (Soler-Rivas, Jolivet, Arpin, Olivier \& Wichers, 1999). Then, this part is wasted and considered as a by-product. This byproduct was submitted to PLE and SFE extractions to investigate whether it could be used as starting material to obtain similar sterols enriched fractions as with the fruiting bodies.

\subsubsection{PLE extractions}

The A. bisporus by-product was submitted to PLE using ethanol as pressurized solvent and selecting the optimal extraction conditions $\left(10.7 \mathrm{MPa}\right.$ at $50^{\circ} \mathrm{C}, 5$ cycles of 5 min, 1:4 mushroom/sand) that according to the obtained results using fruiting bodies, they were appropriated to extract high sterol enriched fractions.

Results indicated that the extraction yields obtained using the stipes $(93.0 \pm 4.2$ $\mathrm{mg} / \mathrm{g})$ were similar than when the whole fruiting body was used $(82.6 \pm 11.9 \mathrm{mg} / \mathrm{g})$ under the same conditions. However, the percentage of sterols in the ASE extracts obtained from the by-product was lower than when fruiting body was utilized (respectively $3.3 \%$ and $6 \%$ ). The ASE extraction process using the by-product extracted approx. $47.5 \%$ of the sterols present in that part of the stipe $(6.4 \pm 0.5 \mathrm{mg} / \mathrm{g})$ while submission of the fruiting body to PLE yielded $60 \%$ of the sterols from the whole sporophore. Certain selectivity within the extracted sterols was also observed depending on the selected starting material since ergosterol was almost $93 \%$ of the sterols present in the extracts obtained from the by-product while in the extracts 
obtained from the fruiting body it represented $85 \%$ of the measured sterols. These differences were probably due to the lower concentration of the minor sterols in the lower part of A.bisporus stipe (Table 1).

\subsubsection{SFE extractions}

The A. bisporus by-product was also subjected to SFE extraction at $40^{\circ} \mathrm{C}$ and $30 \mathrm{MPa}$ during $3 \mathrm{~h}$ using $\mathrm{CO}_{2}$ modified with ethanol $(10 \% \mathrm{v} / \mathrm{v})$. Results indicated that extraction yield obtained when the by-product was used as starting material was lower than when the commercialized fruiting body was utilized since $2.1 \% \mathrm{w} / \mathrm{w}$ dry matter was extracted from the fruiting bodies while $1.4 \%$ was extracted from the discarded stipes. However, the amount of sterols in the extracts obtained from the by-product was $37.25 \%$ while $23.6 \%$ sterols were found in the extracts obtained from the fruiting body. Moreover, the total sterol content of the SFE extract obtained from the mushroom by-product was 5.3 $\pm 0.4 \mathrm{mg}$ sterols $/ \mathrm{g}$ stipes, a slightly higher value than the one observed in the SFE extracts obtained from the commercial fruiting bodies $(4.4 \pm 0.8 \mathrm{mg} / \mathrm{g})$ indicating that the sterols recovery rate from the stipes was higher $(82.8 \%)$ than from whole sporophore (59\%).

As occurred during PLE, preferential extraction of ergosterol instead of the other derivatives was observed when the starting material was the by-product ( $84 \%$ of the total extracted sterols) because when the whole sporophore was utilized, ergosterol was only the $74 \%$ of the total extracted sterols. 
Thus, it could be concluded that ergosterol might also be extracted from this mushrooms by-product using PLE and SFE technologies making this application an interesting alternative method for the commercial valorization of this residue.

\section{Conclusions}

Ergosterol and other minor sterols can be extracted from Agaricus bisporus fruiting bodies and by-products (such as the lower part of the stipe) using PLE and SFE technologies. SFE extractions extracted less material than PLE but the sterol concentration of the obtained fractions was higher (approx. 50\% of the extract) than the PLE obtained fractions (approx. 5\%) thus, SFE was a more selective method and the obtained extracts could be used, for instance, as sterol concentrates or supplements to functionalize foods. However, if the aim of the process is to extract all the sterols from the mushroom, by selecting the proper parameters, PLE is more recommended.

\section{Acknowledgments}

The research was supported by the European Union within the $7^{\text {th }}$ framework programme (7FM-PEOPLE-2009-IIF project 251285), ALIBIRD-CM S2009/AGR1469 regional program from the Community of Madrid (Spain) and AGL2010-21537 national $\mathrm{R}+\mathrm{D}$ program from the Spanish Ministry of Science and Innovation. CTICH is also acknowledged for the cultivation and supplying of the mushrooms fruiting bodies. 


\section{References}

Barajas-Aceves, M., Hassan, M., Tinoco, R., \& Vazquez-Duhalt, R. (2002). Effect of pollutants on the ergosterol content as indicator of fungal biomass. Journal of Microbiological Methods, 50(3), 227-236.

Cheickna, D., \& Hui, Z. (2012). Oat beta-glucan: its role in health promotion and prevention of diseases. Comprehensive Reviews in Food Science and Food Safety, $11(4), 355-365$.

Davis, H. R., Zhu, L. J., Hoos, L. M., Tetzloff, G., Maguire, M., Liu, J., et al (2004). Niemann-Pick C1 like 1 (NPC1L1) is the intestinal phytosterol and cholesterol transporter and a key modulateor of whole-body cholesterol homeostasis, Journal of Biological Chemistry, 279, 33586-33592.

Di, X., Chan, K. K. C., Leung, H. W., \& Huie, C. W. (2003). Fingerprint profiling of acid hydrolyzates of polysaccharides extracted from the fruiting bodies and spores of Lingzhi by high-performance thin-layer chromatography. Journal of Chromatography A, 1018(1), 85-95.

Fan, X., Li, X., Chu, C., Zhang, Z., \& Yan, J. (2012). Optimization of technology for pressurized solvent extraction of lentinan by response surface method. Journal of Chinese Institute of Food Science and Technology, 12(2), 98-104.

García-Risco, M. R., Vicente, G., Reglero, G., \& Fornari, T. (2011). Fractionation of thyme (Thymus vulgaris L.) by supercritical fluid extraction and chromatography. The Journal of Supercritical Fluids, 55(3), 949-954. 
Hammond, J. B. W. (1979). Changes in composition of harvested mushrooms (Agaricus bisporus). Phytochemistry, 18(3), 415-418.

Hsu, R. C., Lin, B. H., \& Chen, C. W. (2001). The Study of Supercritical Carbon Dioxide Extraction for Ganoderma Lucidum†. Industrial \& Engineering Chemistry Research, 40(20), 4478-4481.

Ibrahim Abdullah, M., Young, J. C., \& Games, D. E. (1994). Supercritical fluid extraction of carboxylic and fatty acids from Agaricus spp. mushrooms. Journal of Agricultural and Food Chemistry, 42(3), 718-722.

Jasinghe, V. J., \& Perera, C. O. (2005). Distribution of ergosterol in different tissues of mushrooms and its effect on the conversion of ergosterol to vitamin D2 by UV irradiation. Food Chemistry, 92(3), 541-546.

Jesch, E. D., \& Carr, T. P. (2006). Sitosterol reduces micellar cholesterol solubility in model bile. Nutrition Research, 26(11), 579-584.

Kalač, P. (2009). Chemical composition and nutritional value of European species of wild growing mushrooms: A review. Food Chemistry, 113(1), 9-16.

Kitzberger, C. S. G., Smania, A., Pedrosa, R. C., \& Ferreira, S. R. S. (2007). Antioxidant and antimicrobial activities of shiitake (Lentinula edodes) extracts obtained by organic solvents and supercritical fluids. Journal of Food Engineering, 80(2), 631-638.

Kitzberger, C. S. G., Lomonaco, R. H., Michielin, E. M. Z., Danielski, L., Correia, J., \& Ferreira, S. R. S. (2009). Supercritical fluid extraction of shiitake oil: Curve modeling and extract composition. Journal of Food Engineering, 90(1), 35-43. 
Ling, W. H., \& Jones, P. J. H. (1995). Dietary phytosterols: A review of metabolism, benefits and side effects. Life Sciences, 57(3), 195-206.

Lo, T. C. T., Tsao, H. H., Wang, A. Y., \& Chang, C. A. (2007). Pressurized Water Extraction of Polysaccharides as Secondary Metabolites from Lentinula edodes. Journal of Agricultural and Food Chemistry, 55(10), 4196-4201.

Mattila, P., Lampi, A. M., Ronkainen, R., Toivo, J., \& Piironen, V. (2002). Sterol and vitamin D-2 contents in some wild and cultivated mushrooms. Food Chemistry, 76(3), 293-298.

Mazzutti, S., Ferreira, S. R. S., Riehl, C. A. S., Smania Jr, A., Smania, F. A., \& Martínez, J. (2012). Supercritical fluid extraction of Agaricus brasiliensis: Antioxidant and antimicrobial activities. The Journal of Supercritical Fluids, 70(0), 48-56.

Mendiola, J. A., Herrero, M., Cifuentes, A., \& Ibañez, E. (2007). Use of compressed fluids for sample preparation: Food applications. Journal of Chromatography A, 1152(1-2), 234-246.

Palanisamy, M., Aldars-García, L., Gil-Ramírez, A., Ruiz-Rodríguez, A., Marín F. R., Reglero, G. \& Soler-Rivas, C. Pressurized solvent extraction of mushroom polysaccharides fractions able to scavenge bile acids during in vitro digestion. Journal of Agricultural and Food Chemistry. In Press.

Ramírez-Anguiano, A. C., Santoyo, S., Reglero, G., \& Soler-Rivas, C. (2007). Radical scavenging activities, endogenous oxidative enzymes and total phenols in edible mushrooms commonly consumed in Europe. Journal of the Science of Food and Agriculture, 87(12), 2272-2278. 
Senatore, F., Dini, A., Marino, A., \& Schettino, O. (1988). Chemical constituents of some basidiomycetes. Journal of the Science of Food and Agriculture, 45(4), 337345.

Soler-Rivas, C., Jolivet, S., Arpin, N., Olivier, J. M., \& Wichers, H. J. (1999). Biochemical and physiological aspects of brown blotch disease of Agaricus bisporus. FEMS Microbiology Reviews, 23(5), 591-614.

Teichmann, A., Dutta, P. C., Staffas, A., \& Jagerstad, M. (2007). Sterol and vitamin D-2 concentrations in cultivated and wild grown mushrooms: Effects of UV irradiation. Lwt-Food Science and Technology, 40(5), 815-822.

Thompson, M., Ellison, S. L., \& Wood, R. (2002). Harmonized guidelines for single laboratory validation of methods of analysis (IUPAC Technical Report). Pure and applied chemistry, 74, 835-855.

Turnham, D.I. (1999). Functional foods: cholesterol-lowering benefits of plant sterols. British Journal of Nutrition, 82, 255-256.

Valenzuela B., A., \& Ronco M., A. M. (2004). Fitosteroles y fitoestanoles: aliados naturales para la protección de la salud cardiovascular. Revista chilena de nutrición, 31, 161-169.

Wang, B. J., Won, S. J., Yu, Z. R., \& Su, C. L. (2005). Free radical scavenging and apoptotic effects of Cordyceps sinensis fractionated by supercritical carbon dioxide. Food and Chemical Toxicology, 43(4), 543-552.

Yang, F. Q., Feng, K., Zhao, J., \& Li, S. P. (2009). Analysis of sterols and fatty acids in natural and cultured Cordyceps by one-step derivatization followed with gas 
chromatography-mass spectrometry. Journal of Pharmaceutical and Biomedical Analysis, 49(5), 1172-1178.

Yokokawa, H., \& Mitsuhashi, T. (1981). The sterol composition of mushrooms. Phytochemistry, 20(6), 1349-1351.

Young, J. C., \& Games, D. E. (1993). Supercritical fluid extraction and supercritical fluid chromatography of the fungal metabolite ergosterol. Journal of Agricultural and Food Chemistry, 41(4), 577-581.. 
Table 1: Sterols distribution (mg/g) with in different $A$. bisporus samples.

\begin{tabular}{|c|c|c|c|c|}
\hline & Ergosterol & Ergosta- 7, 22 -dienol & Ergosta-5,7-dienol & Fungisterol \\
\hline \multicolumn{5}{|c|}{ Commercial varieties (spawns) } \\
\hline Fungisem H5 & $5.61 \pm 0.76$ & $0.29 \pm 0.03$ & $0.70 \pm 0.09$ & $0.38 \pm 0.04$ \\
\hline Fungisem H15 & $8.65 \pm 0.69$ & $0.42 \pm 0.17$ & $1.51 \pm 0.20$ & $0.64 \pm 0.11$ \\
\hline Mispaj 365 & $7.40 \pm 0.38$ & $0.29 \pm 0.03$ & $1.23 \pm 0.36$ & $0.47 \pm 0.10$ \\
\hline Gurelan 60 & $5.94 \pm 0.14$ & $0.27 \pm 0.01$ & $0.86 \pm 0.03$ & $0.37 \pm 0.03$ \\
\hline Somycel A15 & $5.15 \pm 0.12$ & $0.30 \pm 0.00$ & $0.99 \pm 0.02$ & $0.50 \pm 0.01$ \\
\hline \multicolumn{5}{|c|}{ Flushes in casing soil 1 (70\% black $30 \%$ blonde peat) } \\
\hline $1^{\text {st }}$ Flush & $4.08 \pm 1.12$ & $0.30 \pm 0.02$ & $0.58 \pm 0.10$ & $0.38 \pm 0.04$ \\
\hline $2^{\text {nd }}$ Flush & $4.20 \pm 0.94$ & $0.30 \pm 0.02$ & $0.60 \pm 0.10$ & $0.37 \pm 0.04$ \\
\hline $3^{\text {rd }}$ Flush & $3.56 \pm 0.20$ & $0.30 \pm 0.01$ & $0.50 \pm 0.03$ & $0.38 \pm 0.01$ \\
\hline \multicolumn{5}{|c|}{ Flushes in casing soil 2 (100\% black peat) } \\
\hline $1^{\text {st }}$ Flush & $3.36 \pm 0.02$ & $0.33 \pm 0.01$ & $0.53 \pm 0.03$ & $0.43 \pm 0.01$ \\
\hline $2^{\text {nd }}$ Flush & $3.64 \pm 0.12$ & $0.33 \pm 0.01$ & $0.58 \pm 0.00$ & $0.44 \pm 0.03$ \\
\hline $3^{\text {rd }}$ Flush & $2.13 \pm 1.04$ & $0.28 \pm 0.06$ & $0.39 \pm 0.14$ & $0.34 \pm 0.08$ \\
\hline \multicolumn{5}{|c|}{ Developmental stages } \\
\hline Primordia (Stage 1) & $4.12 \pm 0.56$ & nd & $0.81 \pm 0.10$ & $0.35 \pm 0.03$ \\
\hline Immature (stage 2-3) & $6.20 \pm 0.11$ & $0.26 \pm 0.01$ & $1.00 \pm 0.02$ & $0.41 \pm 0.04$ \\
\hline Intermediate (stage 4-5) & $4.51 \pm 0.17$ & $0.25 \pm 0.00$ & $0.96 \pm 0.03$ & $0.40 \pm 0.00$ \\
\hline Mature (stage 6-7) & $3.87 \pm 0.23$ & $0.24 \pm 0.01$ & $0.81 \pm 0.06$ & $0.38 \pm 0.02$ \\
\hline \multicolumn{5}{|c|}{ Tissue distribution } \\
\hline Veil & $8.72 \pm 1.09$ & $0.32 \pm 0.01$ & $0.29 \pm 0.02$ & $0.19 \pm 0.01$ \\
\hline Skin & $3.66 \pm 0.28$ & $0.18 \pm 0.02$ & $0.31 \pm 0.05$ & $0.15 \pm 0.02$ \\
\hline Gills & $6.04 \pm 0.29$ & $0.29 \pm 0.02$ & $0.28 \pm 0.03$ & $0.26 \pm 0.02$ \\
\hline Flesh & $3.07 \pm 0.12$ & $0.25 \pm 0.01$ & $0.35 \pm 0.01$ & $0.20 \pm 0.01$ \\
\hline Stipe & $3.91 \pm 0.99$ & $0.18 \pm 0.04$ & $0.15 \pm 0.02$ & $0.13 \pm 0.02$ \\
\hline Lower stipe (by-product) & $4.7 \pm 0.96$ & $0.59 \pm 0.01$ & $0.6 \pm 0.05$ & $0.53 \pm 0.01$ \\
\hline Whole fruiting body & $5.9 \pm 0.95$ & $0.49 \pm 0.15$ & $0.64 \pm 0.14$ & $0.44 \pm 0.19$ \\
\hline
\end{tabular}

nd: not detected 
Table 2: Dry matter content and total sterol concentrations in the ASE extracts obtained at different temperatures.

\begin{tabular}{|c|c|c|c|c|c|c|}
\hline & \multicolumn{2}{|c|}{ Extracted dry matter } & \multicolumn{2}{l|}{ Total sterols in extract } & \multicolumn{2}{l|}{ Total sterols from fruiting bodies } \\
\hline Temperature $\left({ }^{\circ} \mathrm{C}\right)$ & $\mathrm{mg} / \mathrm{g}$ & $\%$ & $\mathrm{mg} / \mathrm{g}$ & $\%$ & $\mathrm{mg} / \mathrm{g}$ & $\%$ \\
\hline 25 & $47.75 \pm 9.00$ & 4.77 & $49.7 \pm 22.20$ & 4.98 & $1.91 \pm 0.60$ & 0.19 \\
\hline 50 & $82.67 \pm 11.90$ & 8.26 & $59.68 \pm 20.32$ & 5.97 & $4.53 \pm 0.50$ & 0.45 \\
\hline 100 & $194.00 \pm 27.00$ & 19.40 & $28.64 \pm 1.31$ & 2.86 & $5.39 \pm 0.76$ & 0.53 \\
\hline 150 & $365.60 \pm 29.01$ & 36.56 & $14.80 \pm 4.63$ & 1.48 & $5.40 \pm 1.70$ & 0.54 \\
\hline 200 & $517.80 \pm 76.6$ & 51.78 & $11.94 \pm 1.61$ & 1.19 & $6.47 \pm 0.77$ & 0.64 \\
\hline
\end{tabular}


Table 3: Extraction yields (\%) and sterol content of extracted fractions from A. bisporus using ASE under different extractions parameters.

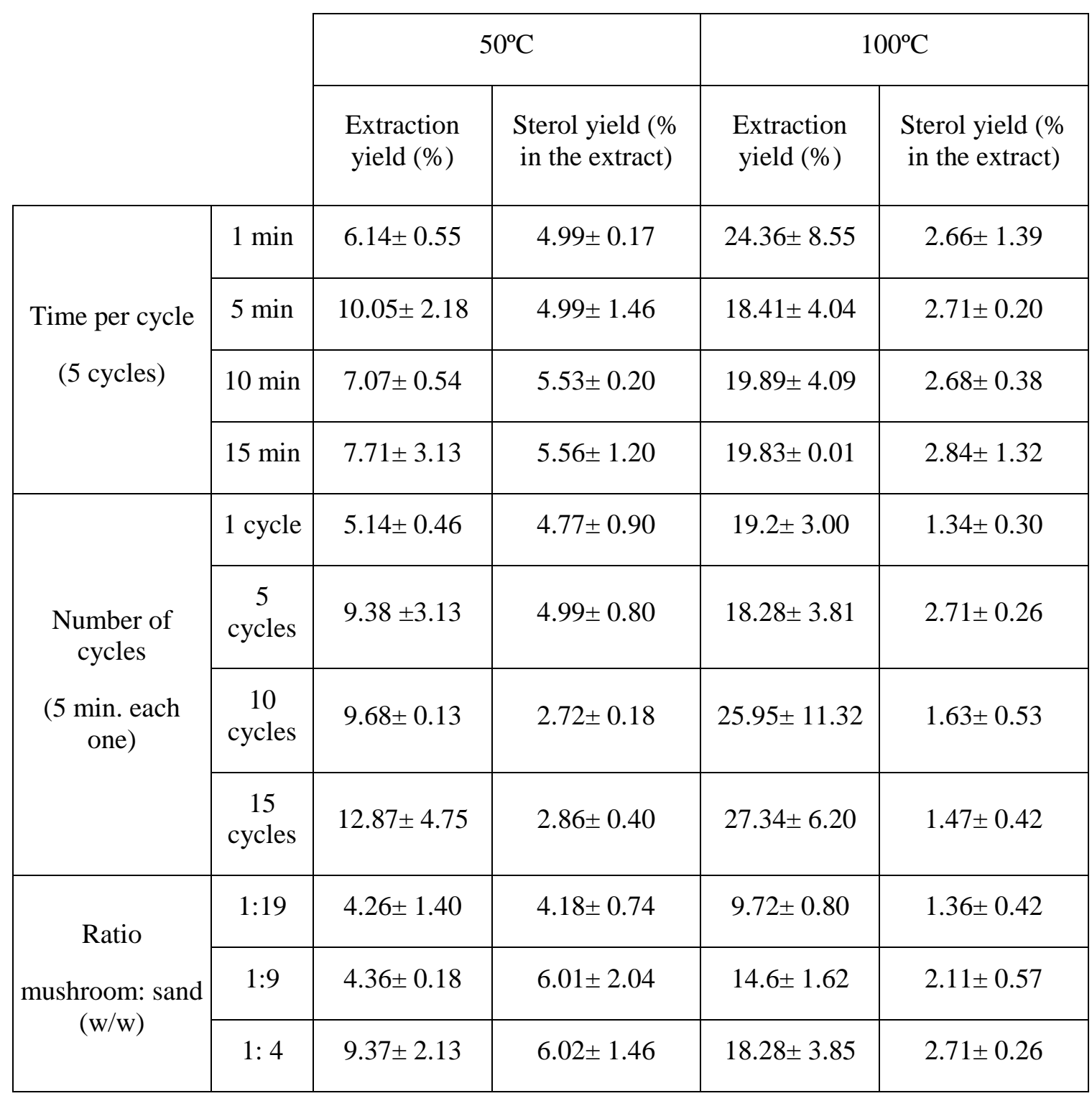


Figure 1: Sterols content $(\mathrm{mg} / \mathrm{g} \mathrm{dw})$ of ASE extracted fractions from A. bisporus at $50^{\circ} \mathrm{C}$ (dark color) and $100^{\circ} \mathrm{C}$ (light color) changing a) extraction time per cycle, b) the number of cycles and c) mushroom: sand ratio. Full bars indicate ergosterol content, dotted bars ergosta-7,22-dienol, diamonds bars ergosta-5,7-dienol and vertical lines fungisterol.

Figure 2: a) Extraction yields and b) sterol content in the SFE extracted fractions from A. bisporus fruiting bodies.

Figure 3: Sterol content (mg/g dw) of SFE fractions extracted from A.bisporus. Dark bars indicate no co-solvent extraction and light one corresponds to an extraction with co-solvent. Full bars indicate ergosterol content, dotted bars ergosta-7,22-dienol, diamonds bars ergosta-5,7-dienol and vertical lines fungisterol. 